\title{
UNA VIDA CONSAGRADA A «LA PALABRA». EL LEGADO LINGÜÍSTICO DEL PROYECTO EVANGÉLICO DE ALBERT Y LOIS BUCKWALTER
}

\author{
A life devoted to "the word". The linguistic legacy of Albert \\ and Lois Buckwalter in the Chaco evangelical project
}

\author{
Agustina Altman \\ IICSAL-CONICET \\ ICA/UBA, Argentina \\ Cristina Messineo \\ UBA-CONICET, Argentina
}

\begin{abstract}
Resumen: Este artículo aborda el proyecto lingüístico del matrimonio de misioneros menonitas formado por Albert Buckwalter y Lois Litwiller Buckwalter en el Chaco argentino. Se basa en fuentes inéditas, en entrevistas personales a Lois L. Buckwalter y en publicaciones de ambos. La labor de la traducción de la Biblia a los idiomas toba, mocoví y pilagá, así como también las decisiones en torno a la elaboración de alfabetos, vocabularios y notas gramaticales, fueron consistentes con el saber lingüístico académico de la época y parte integral de su proyecto evangelizador. Dicha tarea se enmarca en el contexto de un cambio general de paradigma vinculado al creciente rol de la antropología y la lingüística en la formación de los misioneros. El trabajo destaca también el aporte del trabajo del matrimonio Buckwalter a la lingüística chaqueña actual.
\end{abstract}

Palabras clave: menonitas, proyecto lingüístico, toba, mocoví, pilagá, Buckwalter, antropología, Chaco, Argentina.

\begin{abstract}
This article focuses on the linguistic project of the Mennonite missionary couple of Albert Buckwalter and Lois Litwiller Buckwalter in the Argentine Chaco. The analysis is based on unpublished sources as well as personal interviews with Lois L. Buckwalter and publications by both. The work of translating the Bible into the Toba, Mocoví and Pilagá languages as well as the decisions regarding the elaboration of alphabets, vocabularies and grammatical notes were consistent with the academic linguistic knowledge of the time, and an integral part of their evangelizing project. This task is framed in the context of a general paradigm shift linked to the growing role of anthropology and linguistics in the formation of missionaries. The study also highlights the contribution that the work of the Buckwalter couple represents for current Chaco linguistics.
\end{abstract}


Keywords: Mennonites, linguistic project, Toba, Mocoví, Pilagá, Buckwalter, Anthropology, Chaco, Argentina.

\section{Introducción}

Este artículo tiene por objetivo abordar el proyecto lingüístico que el matrimonio de misioneros menonitas formado por Albert Buckwalter y Lois Litwiller Buckwalter llevó adelante durante más de cuarenta años entre los indígenas del Chaco argentino. ${ }^{1}$ Orientados por sus intereses en la evangelización, los Buckwalter ${ }^{2}$ se desempeñaron como lingüistas profesionales y construyeron un proyecto sólido, consistente y duradero que sentó las bases para el estudio contemporáneo de las lenguas indígenas del Chaco argentino.

Si bien la confección de gramáticas y vocabularios en lenguas indígenas fue una labor frecuente en las misiones cristianas en América (Messineo, 2020), la tarea emprendida por el matrimonio Buckwalter a partir de la década de 1950 implicó una profundidad y una centralidad inéditas de la dimensión lingüística, a la vez inmersa en un proyecto misionero. Esta labor se enmarcó en el contexto de un cambio general de paradigma y, en particular, dentro de la iglesia menonita, vinculado al creciente rol de la antropología y la lingüística en la formación de los misioneros. Por esta razón, la comprensión de la cultura local, la preocupación por una incorporación profunda del cristianismo y la relevancia de la lengua en relación con la reapropiación del mensaje cristiano por parte de los grupos indígenas tuvieron un lugar privilegiado en dicha labor.

El aporte lingüístico de los Buckwalter se incluyó dentro de un proyecto evangelizador que buscaba que los grupos indígenas - mediante el acceso a la palabra bíblica en su lengua nativa - llevaran adelante su propio modo de cristianismo evangélico y lo hicieran de manera autónoma. Es este contexto el que permite entender las decisiones en torno a la traducción de la Biblia a los idiomas toba, mocoví y pilagá y a la elaboración de vocabularios y gramáticas, entre otros textos. Dichas decisiones fueron consistentes con el saber académico de la época, a la vez que estuvieron orientadas a cumplir un objetivo específico que tuvo a los propios indígenas como interlocutores centrales. Para comprender este proceso, es vital tener en cuenta el impacto de esta tarea en las

1. Esta investigación se realizó con el apoyo del Consejo Nacional de Investigaciones Científicas y Técnicas de Argentina (CONICET). El acceso a las fuentes y a las entrevistas se obtuvo gracias a la Mennonite Historical Library Grant otorgada a Altman por el Institute for the Study of Global Anabaptism del Goshen College (Indiana, Estados Unidos).

2. Si bien ambos actuaron como equipo durante su trabajo como misioneros, es el nombre de Albert el que figura en las fuentes consultadas. Es posible que las concepciones y prácticas de género propias del cristianismo de la primera mitad del siglo xx contribuyeran a poner en un segundo plano los aportes de Lois (Altman y López, 2015). Además, en la sociedad estadounidense, cuando una mujer se casa, "pierde» su apellido de soltera y adopta el de su esposo. Dado que las fuentes siguen esta práctica, utilizamos el apellido Buckwalter para nombrar a ambos, y del mismo modo en otros casos de matrimonios misioneros nos referiremos a la esposa con el apellido de casada. 
dinámicas socio religiosas de los grupos indígenas chaqueños en los últimos cincuenta años. ${ }^{3}$

La contribución de los Buckwalter en la historia de estos grupos es fundamental no solo en el contexto de la evangelización sino también en el de la educación intercultural bilingüe por su influencia en la escritura de las lenguas indígenas, la alfabetización y la elaboración de textos y materiales didácticos.

Este artículo se basa en una serie de entrevistas realizadas por Agustina Altman y Alejandro López a Lois Buckwalter durante enero de 2019 en Indiana, así como en cartas, diarios de campo, artículos en periódicos menonitas, fotografías e informes, entre otros, del Archivo Menonita de Estados Unidos ubicado en Elkhart (Indiana). Se trata de material inédito, no explorado hasta ahora, y escrito en su mayor parte en inglés, por lo que hemos traducido al español todo lo que aparece citado en este trabajo. Se incorporan también al análisis el Vocabulario toba en sus dos ediciones (Buckwalter y Litwiller de Buckwalter, 2001 [1980]) y un artículo de Buckwalter (1995a). Otra fuente consultada es la gramática inédita del lingüista y antropólogo William Reyburn (1954a), figura crucial para los comienzos del trabajo de los Buckwalter en el Chaco.

El artículo se centra en el período fundacional del trabajo lingüístico de los Buckwalter en el Chaco, que fue desde 1950 hasta 1965. Luego de contextualizar los inicios de la acción misionera menonita en la región y el cambio de paradigma misionero iniciado en la década de 1950, analizamos la labor del matrimonio Buckwalter en relación con las lenguas indígenas, en especial, con el estudio de lengua toba, ${ }^{4}$ tarea que permitió sentar las bases para el trabajo posterior con las lenguas mocoví y pilagá y para la traducción de la Biblia a esos idiomas. Si bien es durante este período cuando pueden verse la raíz y el corazón de su proyecto lingüístico-antropológico-misionero, incorporamos al análisis los trabajos publicados entre 1980 y 2001, ya que representan el resultado de la larga y minuciosa labor anterior. Finalmente, destacamos los aportes lingüísticos de los Buckwalter en el campo del estudio actual de las lenguas aborígenes en el Chaco.

\section{Misioneros menonitas en Chaco y el paradigma de la indigenización}

Las misiones que dieron origen a la presencia menonita en Argentina tuvieron su origen en los Estados Unidos; la Mennonite Church (MC), por medio de la Mennonite Board of Missions and Charities (MBMC) (Altman, 2017).

La experiencia en Argentina comenzó en 1917, cuando Joshepus Shank y Tobias Hershey desembarcaron en Buenos Aires; y en 1919 fundaron en Pehua-

3. Sobre los procesos de cambio religioso entre los indígenas del Chaco, véase, por ejemplo: Altman (2017a); Miller (1979); Wright (2008).

4. Aunque «qom» es la autodenominación actual del pueblo toba y "qom l'aqtaqa» es la de su lengua, a lo largo de este artículo utilizamos el término «toba», en consonancia con su uso en las fuentes consultadas. 
jó la primera congregación menonita de Sudamérica (Altman y López, 2011). Con el transcurso del tiempo, expandieron la obra misionera por la provincia de Buenos Aires (Altman y López, 2011) y en 1943 fundaron en Pampa Aguará, actual provincia del Chaco, la misión Nam Cum entre los aborígenes toba (Altman, 2017; Miller, 1995; Shank, 1951: 43).

Las características centrales del emprendimiento misionero entre los aborígenes del Chaco se articularon en torno al ideal civilizatorio (Ediger, 1999). El establecimiento de una clínica, una granja, una proveeduría y una iglesia tuvieron como objetivo la redención moral de los indígenas mediante un conjunto de prácticas de disciplina, pautas higiénicas e integración en el mercado laboral (Shank, 1951: 42-56).

La fundación de Nam Cum tuvo lugar en un contexto argentino marcado por el golpe militar de 1943 y la llegada al poder de sectores vinculados al integrismo católico (López, 2017). En ese marco, la enseñanza escolar y su lugar en el plan misionero se volvió una cuestión problemática. Si bien los menonitas reconocían la utilidad de las escuelas estatales en la educación de los toba como ciudadanos, las veían como contraproducentes para su formación como fieles cristianos debido a la presión de la Iglesia católica por imponer la enseñanza de su catecismo en las escuelas públicas. Por ello, en las misiones crearon escuelas para niños y adultos que, en concordancia con el ideal civilizatorio, se orientaron a la enseñanza del castellano, aunque debieron enfrentarse al recelo gubernamental ante la presencia de maestros extranjeros.

El ascenso al poder de Juan Domingo Perón, en 1946, supuso un nuevo contexto para las misiones en el Chaco. A través de la Dirección de Protección del Aborigen (1946-1955), el gobierno buscaba «resolver el problema indígena» por medio de la extensión de la «justicia social» y la ampliación del colectivo nacional (D'Addario, 2016). Con este fin, mediante la acción tutelar del Estado, se implementaron medidas asimilacionistas que pusieron el foco en la incorporación protegida de los indígenas a la vida civilizada y en la eliminación de las diferencias en el interior de la nación (Domínguez, 2019; Glozman, 2011).

Al finalizar la Segunda Guerra Mundial comenzó un período signado fuertemente por los procesos de descolonización, que impactaron en las misiones cristianas de todo el mundo y, en el caso particular de la MC, dieron lugar a un replanteamiento global de la actividad misionera. En este contexto, el menonita Joseph Graber fue uno de los principales impulsores del nuevo paradigma de indigenización o indigenization (1960). Para llevarlo adelante, Graber propuso desmantelar las misiones tradicionales de corte imperialista y fomentar la nacionalización de las iglesias (Altman, 2017) y retomó la propuesta del antropólogo Harold Lindsell en la que se hacía referencia al problema que tenían los misioneros para determinar el tipo de «envoltorio» con el que se debía presentar el evangelio (Graber, 1960: 111-113). Las referencias al rol de las culturas locales, el etnocentrismo de los misioneros y la relevancia de la antropología no eran casuales, sino que estaban vinculadas al creciente giro antropológico de las misiones en el ámbito mundial. Así, esta disciplina se incorporó a la formación de los misioneros como una herramienta que permitió arrojar luz sobre las comple- 
jidades que podrían surgir en el establecimiento de las iglesias en contextos culturales diversos. Las ideas de Graber sobre la indigenización cobraron impulso e influyeron en la política de la MC a partir de 1943, cuando este fue elegido secretario general. En ese contexto, Graber centró sus esfuerzos renovadores en las dos misiones más importantes: India y Argentina (Altman, 2017).

Sin estar aún al tanto del nuevo paradigma misionero global, los menonitas en el Chaco habían llegado a un punto crítico en su labor (Altman, 2017). Por un lado, Shank y su esposa, Selena Gamber, que lideraban el grupo de misioneros menonitas entre los indígenas, preparaban su retiro definitivo de Argentina, con lo que se cerraría una etapa importante que se rubricaba con el próximo arribo de una nueva pareja de misioneros para reemplazarlos: Albert y Lois Buckwalter. Por otro lado, se realizaban los preparativos para recibir una serie de visitas oficiales de la MC, cuyo punto culmen fue el arribo al país del propio Graber, en 1952. La correspondencia muestra el gran interés que tales visitas suscitaban entre los misioneros, pero no hay rastro en estas comunicaciones de que en Argentina estuvieran al tanto de los planes que Graber tenía para esas misiones (Altman, 2017).

\section{Dimensiones lingüísticas del cambio de paradigma misionero}

Los Buckwalter provenían de una familia con antecedentes misioneros -Albert era sobrino de Shank y Lois era hija de Nelson y Ada Litwiller, que sirvieron en Argentina entre 1925 y 1956 - y estaban al tanto de las misiones en el Chaco. Interesados en ser parte de ellas, mientras aguardaban su visado, Albert solicitó a la MBMC inscribirse en la Wycliffe Bible Translators, ${ }^{5}$ que ofrecía un curso de lingüística para misioneros. En una entrevista realizada a Lois en 2019, ella nos explicó que Albert «ya tenía interés en eso del idioma, aunque no se le había dado importancia antes». Según nos comentó, en el momento de ser aceptados para asistir al curso, el secretario de Finanzas - que no estaba al tanto de los cambios que se estaban dando en la misiología menonita- los envió a dirigir una escuela parroquial y a enseñar agricultura en Arkansas. Finalmente, en septiembre de 1950, ambos viajaron a Argentina llevando consigo varios libros del lingüista estadounidense Eugene Nida, ${ }^{6}$ con quien habían tomado un curso sobre lingüística misionera y antropología (The Gospel Herald, 1951).

Desde su llegada a Nam Cum, Buckwalter publicó numerosos artículos en el periódico menonita The Gospel Herald, en los que permanentemente hace referencia a la dificultad de los misioneros para comunicarse con los indígenas y a la relevancia de conocer el idioma nativo. Allí señala la necesidad de traducir la Biblia a la lengua toba (Buckwalter, 1952, 1954) y de recurrir a intérpretes

5. Organización fundada en 1942 dedicada a traducir la Biblia a toda lengua viva en el mundo y asociada al Summer Institute of Linguistics.

6. Nida, como secretario de Traducciones de la American Bible Society, impulsó una nueva teoría de la traducción basada en la equivalencia dinámica y formal de las formas lingüísticas (Reyburn, 2002). 
bilingües para saber hasta dónde los indígenas comprendían el mensaje. Su preocupación por sortear la «cortina de hierro del idioma» (Buckwalter, 1953: 399) será el núcleo que dinamizará sus intervenciones en la arena pública del debate menonita sobre las misiones y uno de los primeros aspectos en los que puede verse encarnado el giro antropológico de la nueva generación de misioneros. Para reforzar su argumento, Buckwalter cita en varias oportunidades al lingüista y antropólogo Kenneth Pike, cuyo trabajo le había impactado profundamente.

La relevancia del idioma en el proceso de evangelización no fue un tópico impulsado solo por Buckwalter. Graber (1952: 138) también había insistido en el tema cuando, en su visita a Argentina, presentó el programa de indigenización. Si bien Nam Cum quedó fuera del proyecto de nacionalización administrativa del resto de los emprendimientos misioneros en Argentina (Altman, 2017), no estuvo ajena a las ideas generales sobre la indigenización propuestas por Graber, quien sugirió que los misioneros se trasladasen a las distintas comunidades a evangelizar.

Para ese entonces, los Buckwalter estaban frustrados por los pocos avances que veían en Nam Cum, por lo que decidieron contactar con Nida y solicitarle el envío de un consultor de la Sociedad Bíblica para que los ayudara con la escritura de la lengua toba. Le comunicaron su intención a Graber, y este les sorprendió con su apoyo a la idea. Durante una de las entrevistas, Lois expresó que Nida les había enviado un informe elaborado por un consultor para que ellos evaluaran si les gustaba:

\begin{abstract}
Leímos el informe y era súper [...]. Una de las cosas que nos impresionó era que los misioneros habían estado haciendo culto el domingo a las diez de la mañana y la gente apenas quería venir, estaban medio dormidos. Entonces se dieron cuenta de que esa gente tenía la costumbre de madrugar y para esa hora de la mañana ya estaban para la siesta. Entonces cambiaron la hora de la reunión y santo remedio. Entonces cosas así nos impresionaron. Entonces vino Reyburn con la esposa, ${ }^{7}$ él tenía un doctorado en Lingüística y Antropología y ella había enseñado antropología, así que estaban muy bien capacitados.
\end{abstract}

En abril de 1954 los Reyburn arribaron al Chaco con el objetivo de estudiar la lengua toba, proporcionar herramientas antropológicas a los misioneros y brindarles sugerencias metodológicas. Cuando la entrevistamos, Lois recordaba que, durante la estadía de los Reyburn:

\footnotetext{
[Albert y Reyburn] decidieron visitar otras comunidades indígenas, en Pampa del Indio especialmente porque decidieron ir a donde los toba de Nam Cum tenían parientes para tener una conexión, y es cuando se encontraron con el movimiento evangelístico, un contraste tremendo. Con gente que no se beneficiaba de nada porque los pastores que venían más bien le daban órdenes y si no obedecían no los volvían a visitar, pero por fuera de eso no tenían nada para ofrecerles y sin embargo la energía, tremenda. Y eso nos abrió los ojos.
}

7. Ambos trabajaron para la American Bible Society, cuyo secretario de Traducciones era Nida (Reyburn, 2002). 
Tras seis meses de trabajo, Reyburn (1954c) presentó un informe final en el que describe el proceso de cambio social y religioso entre los toba, especialmente sus resignificaciones de la experiencia cristiana. En un artículo en The Gospel Herald (Reyburn, 1954b: 615), se refiere al surgimiento de un culto de «tipo pentecostal» que los indígenas realizan en su propio idioma y que encaja con sus esquemas de pensamiento y su forma de expresión emocional. También destaca que los toba «no están apegados a ninguna denominación» -en el sentido de que no tienen preferencia por ninguna iglesia cristiana en particular-, que les gusta reunirse, cantar, y que, si bien recitan la Biblia durante la prédica, no logran captar su significado, porque no entienden el castellano. Por esta razón, Reyburn sugirió disolver la misión y ayudar a los creyentes en la comprensión del texto bíblico mediante la urgente traducción de la Biblia a la lengua toba, con el objetivo de que la iglesia toba dejase atrás su «infantilidad». Además de estas sugerencias, Reyburn (1954a) elaboró una gramática del idioma toba que sería fundamental para el estudio posterior de esta lengua.

Finalizado el trabajo de Reyburn, el grupo de misioneros decidió seguir su consejo, disolver Nam Cum y acompañar a los toba en su propia elaboración del cristianismo. ${ }^{8}$ A partir de ese momento, el trabajo de los menonitas en Chaco se focalizó especialmente en la traducción bíblica y en la elaboración de materiales pastorales, ${ }^{9}$ lo que requirió no solo el estudio de la gramática sino también la toma de decisiones ortográficas que favorecieran simultáneamente la alfabetización en castellano. ${ }^{10}$ De este modo, la lengua resultó ser el eje fundamental de la acción futura de los menonitas y de la cristalización del giro antropológico de sus misiones en el Chaco, giro que también fue lingüístico.

La nueva misión encontró la resistencia de Shank, quien, como fundador de la presencia menonita en Argentina, tuvo gran peso simbólico, tal como se observa en la carta que Nelson Litwiller - secretario general de las misiones menonitas en Argentina y padre de Lois - le escribe a Shank para informarle sobre la disolución de Nam Cum como resultado del informe de Reyburn. ${ }^{11}$ Allí Litwiller le confiesa que es una carga comunicarle que la misión que había fundado dejaría de existir, pero que ello no significaba que su trabajo y años de dedicación no fueran valorados. Destaca que el informe de Reyburn es una pieza antropológica y lingüística asombrosa que se enmarca en el programa de indigenización. Además, le dice que será un requisito que desde ese mo-

8. Con el transcurso del tiempo, los menonitas participaron en el surgimiento de la primera Iglesia aborigen autónoma legalmente reconocida: la Iglesia evangélica unida, y brindaron asesoramiento para que fuese inscrita en el Registro de Cultos de Argentina, requisito obligatorio para las confesiones religiosas no católicas.

9. Por ejemplo, el boletín Qad'aqtaxanaganec ('nuestro mensajero'), que incluía tanto avisos y noticias sobre la IEU como textos y comentarios bíblicos, muchos de ellos en las lenguas indígenas, lo que influyó en las elecciones lingüísticas, dialectales y ortográficas de la traducción de la Biblia (Altman, 2017a).

10. Mennonite Church USA Archives, A. y L. Buckwalter Papers HM1-097, serie 1, caja 4, carpeta 7: Buckwalter Albert (1954). Remarks concerning a literacy program, ff. 1-4.

11. Mennonite Church USA Archives, A. y L. Buckwalter Papers HM1-097, serie 1, caja 4, carpeta 8: Nelson Litwiller (1954). Carta a J. Shank y Gamber, S. Paraguay, ff. 1-4. 
mento todos los misioneros tengan un adecuado dominio del idioma toba, ya que este sería el puente (psicológico, cultural y lingüístico) que utilizarían los menonitas a la hora de comunicarse. ${ }^{12}$ En su respuesta, Shank cuestiona de manera minuciosa el nuevo rumbo. Si bien se muestra de acuerdo con el uso de la lengua indígena en la comunicación del mensaje cristiano, destaca que «la política del gobierno hace énfasis en alfabetizar a los aborígenes en el idioma del país», ${ }^{13}$ por lo que él se sentiría "condenado" si les enseñase a los niños toba a leer en su propio idioma, cuando el gobierno no lo aprobaba. Señala, además, que la «ambición» de los propios indígenas es aprender el idioma español, por lo que no entiende «por qué no habría que ayudarlos de todas las formas posibles». ${ }^{14}$

Algo similar observamos en la carta que Buckwalter le escribe a Shank, donde le dice que el informe de Reyburn, sus sugerencias y su gramática han cambiado el programa de la misión. De acuerdo con Reyburn, «tenían frente a sus ojos una iglesia indígena, que debían aceptarla tal cual era y que para poder acceder al alma de los indígenas lo debían hacer a través del idioma que estos utilizan cotidianamente: el toba». ${ }^{15}$ Buckwalter enfatiza que solo así podrían comunicar las profundas verdades de Dios, ya que es a través del toba que los indígenas viven, aman, piensan y creen. Además, destaca que «el profundo deseo de los toba es aprender a leer en español», ${ }^{16}$ por lo cual es necesario elaborar materiales bilingües y adaptar el alfabeto toba al del español, para así minimizar las confusiones y poder alfabetizarlos simultáneamente en ambas lenguas. ${ }^{17}$ Preocupado por la postura de Shank, Buckwalter subraya que esta nueva tarea lingüística se debe a que «ilos indios quieren la Biblia! ¿Qué más podríamos pedir? Los temas serán sobre la Biblia. Los indios querrán leerlos y el resultado será que leerán comprendiendo».18

La respuesta de Shank es contundente. Entre diversas críticas y dudas, señala que le parece correcto que los misioneros aprendan toba, pero solo con el fin de entender y regular lo que los indígenas predican. Insiste en que es una pérdida de tiempo alfabetizarlos en toba y que el énfasis debería estar puesto en el castellano, ya que los indígenas están siendo introducidos cada vez más al «mundo blanco». ${ }^{19}$ Además, destaca que esto es lo que el gobierno quiere y que los misioneros deberían colaborar en dicha tarea; en palabras de Shank: «no creo que los misioneros deban perder su tiempo enseñándole a las masas a leer toba. Además, creo que el gobierno objetará si se enteran de lo que es-

12. Ídem.

13. Mennonite Church USA Archives, A. y L. Buckwalter Papers HM1-097, serie 1, caja 4, carpeta 8: Shank Josephus (1954). Carta a N. Litwiller, USA, f. 2.

14. Ídem.

15. Mennonite Church USA Archives, A. y L. Buckwalter Papers HM1-097, serie 1, caja 4, carpeta 8: Buckwalter Albert (1954). Carta a J. Shank, f. 1.

16. Ibídem, f. 2.

17. Ídem.

18. Ídem.

19. Mennonite Church USA Archives, A. y L. Buckwalter Papers HM1-097, serie 1, caja 4, carpeta 8: Shank Josephus (1954). Carta a A. Buckwalter, f. 1. 
tán haciendo». ${ }^{20}$ Por último, sugiere que el énfasis que Reyburn ponía en la lingüística se debía a un sesgo profesional. ${ }^{21}$

Buckwalter responde que no se trata de abandonar el esfuerzo misionero, sino de usar otra metodología, ya que los toba aceptaron el cristianismo de un modo que es inteligible para ellos, por lo cual solo necesitan las herramientas adecuadas. De esta manera, sostiene, la alfabetización en toba no suplantará el castellano, sino que los materiales serán bilingües y los propios indígenas podrán decidir qué idioma usar. Finalmente, reconoce que probablemente el gobierno objete esta injerencia, pero que están dispuestos a correr un riesgo que a largo plazo será positivo para los propios indígenas. ${ }^{22}$

Más allá de estos debates con Shank, los Buckwalter debieron afrontar otro desafío: el apoyo oscilante de la MBMC. Esto se observa en la correspondencia de Buckwalter con Reyburn, donde aquel le pide a este asesoramiento para solicitar financiación a la MBMC, para capacitarse formalmente como lingüista y para llevar adelante la traducción de la Biblia. ${ }^{23}$ Reyburn le sugiere que base su argumentación en la petición de los propios indígenas de ser alfabetizados y en el deseo, tanto de cristianos como de no cristianos, de leer las Escrituras, y le dice que para ello debe formarse con los «últimos métodos en lingüística y alfabetización con el objetivo de lograr las demandas de la iglesia toba en un contexto de aculturación». ${ }^{24}$ Le advierte también de que, aunque dicha tarea requiera entrenamiento en el análisis lingüístico, no hay necesidad de convocar a especialistas externos, ya que en el corto plazo el propio Buckwalter será no solo un «experto lingüista», sino también el único «experto en toba». ${ }^{25}$

Los Buckwalter, que, como ya hemos mencionado, habían recibido capacitación en lingüística antes de arribar a Argentina, siguieron el consejo de Reyburn y reforzaron sus conocimientos con cursos en Wycliffe Bible Translators, Kennedy School of Missions y el Summer Institute of Linguistics (Buckwalter, 1987). De este modo, adquirieron una formación académica en lingüística a la vez que tuvieron como meta principal la evangelización y la traducción de la Biblia a las lenguas chaqueñas.

Una muestra del reconocimiento de su labor como expertos puede encontrarse en las expresiones de aprecio y admiración por su trabajo por parte de lingüistas internacionales, como Reyburn y Nida, así como también por parte de académicos del medio local, como es el caso de Salvador Bucca, que en ese momento ocupaba el cargo de director del Instituto de Lingüística de la Facultad de Filosofía y Letras de la Universidad de Buenos Aires. La relevancia del re-

20. Ídem.

21. Ídem.

22. Mennonite Church USA Archives, A. y L. Buckwalter Papers HM1-097, serie 1, caja 4, carpeta 8: Buckwalter Albert (1954). Carta a J. Shank, f. 3.

23. Mennonite Church USA Archives, A. y L. Buckwalter Papers HM1-097, serie 1, caja 4, carpeta 7: Reyburn William (1955). Carta a A. y L. Buckwalter, f. 1.

24. Ídem.

25. Ídem. 
conocimiento oficial local para los Buckwalter y, en especial, para los propios tobas puede verse en la petición de apoyo institucional que los Buckwalter le solicitaron a Bucca en 1958 para la tarea emprendida con la lengua toba. ${ }^{26}$

En 1955 un golpe de Estado en Argentina derrocó al presidente Perón. Esto provocó, entre otras consecuencias, la desaparición de las regulaciones peronistas en materia de política indígena (D’Addario, 2016; Gordillo y Hirsch, 2010: 25) y el endurecimiento de la regulación y control sobre los cultos no católicos (López, 2017). En esas circunstancias, adversas a las misiones no católicas en Argentina, la disolución de Nam Cum permitió a los menonitas que su acción en el Chaco pasara más desapercibida para las nuevas autoridades.

\section{Entre la experticia y el volver nativo el mensaje. La contribución de los Buckwalter a la lingüística chaqueña}

Aunque la labor lingüística más conocida de los Buckwalter es la traducción de la Biblia a los idiomas guaicurúes (toba, mocoví y pilagá) junto con la elaboración de diccionarios, vocabularios y un breve esquema gramatical de la lengua toba, ${ }^{27}$ su tarea trasciende ampliamente estos objetivos.

En el nutrido intercambio epistolar con lingüistas coetáneos, como Reyburn, Nida y Bucca, se evidencia la preocupación de Buckwalter por el análisis minucioso y preciso de los rasgos de lenguas antes no bien documentadas (en particular, de la lengua toba), así como también de la necesidad de volver nativo el mensaje. En este doble proceso, la lingüística y la antropología de la época influyen de manera decisiva en su mirada sobre las lenguas y las culturas chaqueñas, a la vez que constituyen herramientas adecuadas para trasmitir de manera clara y simple el mensaje cristiano y capacitar a los propios indígenas como traductores bíblicos.

Al respecto, en una de sus cartas dirigidas a Nida, Buckwalter expresa claramente que los principales interlocutores de su labor lingüística son los indígenas y no los lingüistas ni los académicos:

\footnotetext{
Mi consideración básica al respecto es hacer esto lo más simple posible. No hice este diccionario para guardarlo en las bibliotecas de las universidades, pero al mismo tiempo tampoco tuve la intención de burlarme de la ciencia lingüística [...]. Quise que los indígenas fueran ellos mismos capaces de utilizar el libro sin mayores dificultades o distracciones. Esta es una de las razones por las cuales no identifiqué las partes de la oración, sino que más bien traté de darle a cada palabra la traducción más exacta posible para permitir así que los lingüistas determinen por sí mismos a qué forma equivale cada una. ${ }^{28}$
}

26. Mennonite Church USA Archives, A. y L. Buckwalter Papers HM1-097, serie 1, caja 1, carpeta 15: Buckwalter Albert (1958). Carta a S. Bucca, ff. 1-3.

27. Buckwalter (1972; 1995b); Buckwalter y Litwiller de Buckwalter (2001; 2001 [1980]; 2004); Sociedad Bíblica Argentina (1980; 1991; 1993a; 1993b; 2005 [1988]).

28. Mennonite Church USA Archives, A. y L. Buckwalter Papers HM1-097, serie 1, caja 4, carpeta 3: Buckwalter Albert (1981). Carta a E. Nida, f. 2. 
En un estilo sencillo, el Vocabulario toba y su Apéndice gramatical (Buckwalter y Litwiller de Buckwalter, 2001 [1980]) documentan de manera precisa rasgos y categorías gramaticales del idioma toba, inusuales o no existentes en las lenguas europeas más conocidas y de relevante interés tanto para la lingüística chaqueña como para la tipología lingüística en general. Se trata de un vocabulario y de una gramática respetuosos con la estructura del idioma y, a la vez, adecuados para ser comprendidos por los propios hablantes nativos. Con esta armónica combinación, la obra sigue siendo hasta el momento una de las descripciones gramaticales más completas sobre el idioma toba y es fuente de consulta no solo de los especialistas en las lenguas guaicurúes, sino también de los lingüistas y antropólogos interesados en las lenguas y culturas chaqueñas.

Las decisiones sobre la escritura y la traducción de la Biblia -muchas de ellas basadas en el estudio preliminar de Reyburn (1954a) - Ilevan a Buckwalter a meditar sobre diversos problemas lingüísticos, los estilos de narrar en toba y la importancia del aprendizaje bilingüe y la alfabetización tanto en la lengua indígena como en español. Las reflexiones surgidas del diálogo de Buckwalter con los mencionados lingüistas dan cuenta de su capacitación y destreza para resolver dichos problemas, algunos de los cuales se tratan en los apartados siguientes.

\subsection{El problema de la escritura y el sistema fonológico}

Las decisiones sobre cómo escribir las lenguas y qué tipo de alfabeto utilizar están en todos los casos tamizadas por la tensión entre el criterio estrictamente lingüístico y la accesibilidad y beneficio que un alfabeto debe aportar a los propios hablantes nativos. Este esfuerzo por hacer accesibles los conocimientos lingüísticos y, a la vez, respetar la estructura fonológica de las lenguas es un tópico recurrente en los intercambios epistolares entre Buckwalter y los lingüistas con los que dialoga, en particular, con Reyburn. Así, también hace referencia a «algunos exploradores, investigadores y principalmente sacerdotes [...] que generalmente no captaban, o no alcanzaban a detectar la oclusión glótica" (Buckwalter, 1995a: 123), es decir, el sonido glotal / //, característico de muchas lenguas chaqueñas. Otro contraste que, según Buckwalter (1995a: 124), no percibieron investigadores y misioneros es el de la serie de velares y posvelares sordas y sonoras respectivamente (/k/-/q/;/g/-/G/). Y advierte también sobre el hecho de que el mismo fenómeno ocurre en los hablantes indígenas, que no distinguen entre las vocales del castellano /o/ y /u/, ya que su sistema fonológico carece de $/ u /$. Y, dentro de las lenguas de la familia guaicurú, señala que, mientras que los hablantes de toba y pilagá no perciben el contraste fonológico entre las consonantes / $/$ / y / $/$ / del español, los hablantes del mocoví sí las distinguen, porque poseen en su lengua tal contraste (Buckwalter, 1995a: 125). Aunque sin mencionarlo de manera explícita, Buckwalter se refiere al concepto "sordera fonológica», acuñado por el lingüista ruso Nikolái Trubetskói (Trubetzkoy, 1973 [1939]), por el cual un hablante está preso de su propio sistema fonológico y le cuesta oír y diferenciar los sonidos de otras lenguas que no son las propias o conocidas. 
Un aspecto interesante que surge de las reflexiones en torno al alfabeto es el de la necesidad de profundizar en el análisis gramatical de las lenguas y el reconocimiento de que el sistema de escritura está directamente ligado también a problemas morfosintácticos, como sucede con la alternancia fonológica del prefijo de negación sa- saq-. Un ejemplo de esto es la discusión en torno a la distribución de los sonidos glotal oclusivo / $/$ y glotal fricativo / $h$ / delante de las vocales cuya selección fonética/fonológica soluciona a la vez el problema de la negación, expresada mediante los prefijos arriba mencionados. Ambos aspectos se discuten extensamente en varios intercambios epistolares entre Buckwalter y Reyburn. ${ }^{29}$ La conclusión a la que llegan respecto de la distribución de la oclusión glotal $/ / / 30$ o «saltillo», como Buckwalter denomina a este fonema, es la siguiente:

También chequeé las vocales en el límite de palabras. Encontré que (') ocurre delante de $a$, e y o, pero nunca delante de $i$. El sonido $h^{31}$ ocurre delante de $a, e, i$, pero nunca delante de $o ; h$ se elide delante de $a$ y de $i$, pero nunca delante de $e ; h$ delante de $i$ está en libre variación con cero. Esto nos deja con el problema de si escribir o no $h$ delante de a. Para empezar, tenemos el par mínimo /alo/ 'mujer' y /jalo/ 'ceniza'. Por supuesto, 'a- no se elide pero ja- se elidió en todos los casos. ${ }^{32}$

En respuesta a esta carta, Reyburn le propone analizar dichos sonidos de la siguiente manera: $[h]$, aspiración fonética que ocurre delante de /a/ y raramente de /i/; y /j/, fonema que ocurre solo delante de /e/. ${ }^{33}$

Entonces, el sistema fonológico del toba en relación con los sonidos $/ h / \mathrm{y} / \mathrm{j} / 34$ y las vocales se resuelve de la siguiente manera:

\begin{tabular}{|c|c|c|c|}
\hline \multicolumn{2}{|c|}{ Representación fonológica } & \multicolumn{2}{|c|}{ Ejemplos } \\
\hline Pa- & $\neq(h) a-$ & Palo ('mujer’) & $\neq$ alo halo ('ceniza') \\
\hline Pe- & $\neq j e-$ & Pepaq ('árbol') & $\neq$ jek ('se va') \\
\hline Pi- & $\neq(h) i-$ & Pik ('tu camino') & f (h)ima ('todo') \\
\hline ?O- & & Ponaxaik ('es linc & , es bueno') \\
\hline
\end{tabular}

Una interesante observación de Buckwalter al respecto es la siguiente: «los tobas son conscientes de la distinción entre 'a y ja y aunque nunca pronuncian ja (jalo, na jalogo) en el habla cotidiana, ellos escriben $j$ delante de a para distinguir de 'a ('alo, 'mujer'; jalo, 'ceniza')»..$^{35}$

29. Mennonite Church USA Archives, A. y L. Buckwalter Papers HM1-097, serie 1, caja 4, carpeta 7 .

30. Aquí Buckwalter utiliza el símbolo ' para representar gráficamente el fonema glotal $/ ? /$.

31. Aquí Buckwalter utiliza $/ \mathrm{h} / \mathrm{y} / \mathrm{j} /$ de manera indistinta.

32. Mennonite Church USA Archives, A. y L. Buckwalter Papers HM1-097, serie 1, caja 4, carpeta 7: Buckwalter Albert (1954). Carta a W. Reyburn, 1 de noviembre de 1954, f. 3.

33. Mennonite Church USA Archives, A. y L. Buckwalter Papers HM1-097, serie 1, caja 4, carpeta 7: Reyburn William (1955). Carta a A. Buckwalter, f. 1.

34. El signo $j$ corresponde al sonido $/ x /$ (velar fricativo sordo) del alfabeto fonético internacional.

35. Mennonite Church USA Archives, A. y L. Buckwalter Papers HM1-097, serie 1, caja 4, carpeta 7: Buckwalter Albert (1954). Carta a W. Reyburn, 20 de diciembre de 1954, f. 1. 
Ya sea por intuición, ya sea por conocimiento de la obra de Edward Sapir (1949), Buckwalter expresa con claridad y simpleza la idea de que los hablantes poseen plena consciencia del valor distintivo de los fonemas de su propia lengua. Entonces, al reconstruir este patrón fonológico, Buckwalter resuelve el problema de la distribución de los prefijos de negación, tal como se observa en su intercambio con Reyburn, quien le sugiere la siguiente solución:

[...] tenemos hanac y saq anac (no ahora saq janac), hanaq será /anac/ todas las veces y se pronunciará con una aspiración solo cuando esté en posición inicial. En su forma aislada será hashec, hawot, haso, hayem, etc. Entonces, [al agregar la negación] se escribirán $\sin / j /=[h]$ : saq awot, saq atom. ${ }^{36}$

El problema de la escritura lo lleva también a reflexionar acerca del carácter convencional de los símbolos alfabéticos: «los símbolos son simplemente símbolos, representaciones gráficas de un idioma dado» (Buckwalter, 1995a: 126). Y este será el principio que lo conducirá, de manera convincente, a solucionar los problemas con sonidos como el postvelar fricativo sonoro/G/, que propone representar con la letra $x$, o como el de la semiconsonante palatal $y$, que escribe $\tilde{y}$ para diferenciarla de la letra $y$, que representa al sonido palatal fricativo sonoro /j/, como el del español rioplatense en el pronombre de primera persona singular/yo/:

[...] una de las convenciones es ocupar la letra $\underline{\mathbf{x}}$ para simbolizar cualquier consonante que no tiene equivalente en el castellano, ya que la letra $\underline{x}$ ocurre con poca frecuencia en castellano, y así puede desempeñar una doble función: el sonido $\underline{\mathbf{c s}}$ en castellano y el sonido posvelar fricativo sonoro en toba, mocoví y pilagá. La letra ỹ fue confeccionada para representar la semiconsonante que ocurre en los tres idiomas en cuestión. En toba y mocoví se necesita esta letra especial para distinguir este sonido del de la $\underline{\mathbf{y}}$ castellana argentina. Por ejemplo, en toba se dice:

$\begin{array}{ll}\text { noỹic } & \text { casa } \\ \text { noyic } & \text { quebracho blanco }\end{array}$

\section{ỹamaq le manda yamaq me manda}

(Buckwalter, 1995a: 126). ${ }^{37}$

Su preocupación por que los indígenas sean los destinatarios se manifiesta también en su interés por simplificar el alfabeto toba y adaptarlo, en la medida de lo posible, a los grafemas del castellano: «Los indígenas desean aprender español, entonces [...] si aprenden a leer por medio de su propia lengua y se les proporciona material bilingüe (español-toba), esto será de gran ayuda».38

Las cuestiones prácticas de imprenta, los contrastes y similitudes entre las lenguas guaicurúes, las diferencias dialectales y, en especial, su preocupación por la necesidad de que los indígenas accedieran a una alfabetización simultánea del castellano y del idioma nativo son las principales razones para proponer un alfabeto práctico, unificado y lo más semejante posible al del español.

36. Mennonite Church USA Archives, A. y L. Buckwalter Papers HM1-097, serie 1, caja 4, carpeta 7: Reyburn W. (1955). Carta a A. Buckwalter, 4 de febrero de 1955, f. 2.

37. La negrita es del original.

38. Mennonite Church USA Archives, A. y L. Buckwalter Papers HM1-097, serie 1, caja 4, carpeta 7: Buckwalter Albert (1958). Carta a S. Bucca, f. 3. 


\subsection{Escritura, lenguas emparentadas y dialectos}

Buckwalter identifica de manera muy precisa las diferencias entre los dialectos del toba y las lenguas emparentadas, como el pilagá y el mocoví. En sus intercambios con Reyburn menciona la existencia y el contacto entre variedades dialectales en Nam Cum así como las diferencias que detecta en sus encuentros con hablantes de distintas localidades de la región..$^{39}$

Una de las diferencias más sistemáticas es la presencia de una aspiración delante de la vocal a inicial: «donde nuestra gente [de Nam Cum y El Espinillo] pronuncia a-, él pronuncia ja- (/h/), la mayoría de las veces». ${ }^{40}$ Otra es la variación existente entre /s-/ y /j/, al inicio y seguidas de vocales /a/ y /o/, como, por ejemplo, ja jayaten en vez de sa sayaten, ambos con el significado de 'yo no sé'. En este punto, Buckwalter hace referencia a sus conversaciones con Alfred Leake - responsable de la Misión Anglicana en la provincia de Formosa-, para quien el idioma tiene «un grupo s-y otro grupo $j$-», y que en su traducción al toba del Libro de los Actos usó jiyagaua ('nuestra gente') en vez de shiaxaua. ${ }^{41}$

No obstante, Buckwalter reconoce que estas diferencias no impiden la inteligibilidad entre hablantes de distintas localidades, ya que los tobas no solo se entienden entre sí, sino que también pueden identificar las diferencias e indicar su procedencia. Asimismo, aunque sistematiza algunos contrastes entre las lenguas toba, pilagá y mocoví, remarca la notable similitud entre estas y sostiene que una ortografía común facilita la lectura en los tres idiomas. Señalar tales diferencias, sostiene Buckwalter, solo sirve para identificar variedades dialectales o los contrastes entre las lenguas emparentadas, ${ }^{42}$ pero no es útil al objetivo de proponer un alfabeto unificado que permita leerlas y escribirlas. $Y$ afirma también que «los mismos nativos del Chaco reconocen que están emparentados entre sí, tanto por familiares como por idiomas, razón suficiente como para usar un alfabeto único en lo posible, para honrar, realzar y afianzar esa unidad natural» (Buckwalter, 1995a: 126).

Asimismo, destaca la dificultad de publicar libros en un idioma en el cual se carece de un modelo, lo que requiere tomar decisiones concretas que no siempre conformarán a todos, más allá de las diferencias dialectales. Estas decisiones y otras respecto del léxico y la gramática constituyen el resultado de un diálogo continuo con expertos, como Reyburn y Nida, quienes le aconsejaron enfocarse en la escritura y en la traducción y dejar de lado, por el momento, los problemas gramaticales y dialectales. ${ }^{43}$

39. Mennonite Church USA Archives, A. y L. Buckwalter Papers HM1-097, serie 1, caja 4, carpeta 7: Buckwalter Albert (1955). Carta a W. Reyburn, 26 de marzo de 1955, f. 1.

40. Ídem.

41. Mennonite Church USA Archives, A. y L. Buckwalter Papers HM1-097, serie 1, caja 4, carpeta 7: Buckwalter Albert (1955). Carta a W. Reyburn, 2 de marzo de 1955, f. 2.

42. El Vocabulario toba no hace prácticamente ninguna referencia a las diferencias dialectales, aunque menciona las distintas parcialidades, lo que indica un detallado conocimiento de la situación etnodialectal toba.

43. Mennonite Church USA Archives, A. y L. Buckwalter Papers HM1-097, serie 1, caja 4, carpeta 7: Reyburn William (1955). Carta a A. Buckwalter y famila, f. 2 '55. 
Esta preocupación por la unificación lingüística obedeció principalmente a la necesidad de borrar las diferencias en pro de volver simple y asequible el mensaje bíblico. Así pues, un alfabeto único y la producción de material bilingüe facilitaría que los hombres accedieran a una alfabetización bilingüe y que la transmitieran a las mujeres en el ámbito doméstico. ${ }^{44}$ Por último, si bien Buckwalter era absolutamente consciente de la compleja situación dialectal del idioma toba, su trabajo lingüístico se circunscribió a las variedades habladas por sus colaboradores en el proceso de traducción de la Biblia, la mayoría de ellos provenientes de Pampa Aguará y El Espinillo.

\subsection{Más allá de las convenciones ortográficas. Soluciones gramaticales a problemas complejos y tipológicamente inusuales}

Si hay algo que llama la atención en el Vocabulario toba y, en especial, en el apéndice (Buckwalter y Litwiller de Buckwalter, 2001 [1980]) es el tratamiento de ciertas categorías gramaticales nunca antes descritas con tal precisión y exhaustividad en las lenguas de la región. Como apunta el lingüista Bucca en el prólogo de la edición de 1980 (Buckwalter y Litwiller de Buckwalter, 2001 [1980]: v-vi), la obra difiere de las anteriores porque «en ellas se observan las influencias de la lingüística moderna y no se tiene presente el modelo de la gramática latina[,] que es muy evidente sobre todo en la gramática atribuida a Bárcena y en la de Ducci». Y en referencia a su accesibilidad, agrega: «Los apuntes gramaticales son claros y cumplen perfectamente con su fin[,] que no quiere ser el de una presentación técnica».

Además de las discusiones e intercambios sobre aspectos gramaticales recopilados de las fuentes consultadas, le dedicaremos especial atención a algunos rasgos tipológicamente inusuales de la lengua toba y al tratamiento que Buckwalter les da en su esbozo gramatical.

En primer lugar, se destaca su preocupación por comprender el significado y la función de las palabras en contextos sintácticos más amplios. Por ejemplo, reflexiona sobre la necesidad de trabajar con oraciones completas y no con palabras sueltas, ${ }^{45}$ "ya que en el trabajo de traducción los tobas hacen todo el tiempo conexiones de las palabras con otras». ${ }^{46}$ Mencionamos arriba el caso de la alternancia sa- saq- de la negación, cuya distribución resuelve apelando a contextos fonológicos más amplios. Otro ejemplo de su aguda reflexión lingüística es la discusión sobre si ciertas formas deben considerarse morfemas ligados o independientes, como sucede con la forma l'ec, que aparece tanto en construcciones del tipo menaxanaxaqui l'ec ('almacenero') y netaxat l'ec ('lo que está dentro del

44. Mennonite Church USA Archives, A. y L. Buckwalter Papers HM1-097, serie 1, caja 4, carpeta 7: Buckwalter Albert (1954). Remarks concerning a literacy program, f. 3.

45. Se observa aquí la influencia de Kenneth Pike, quien, desde una perspectiva enmarcada en la teoría tagmémica, propone relacionar las unidades lingüísticas con su función en la sintaxis.

46. Mennonite Church USA Archives, A. y L. Buckwalter Papers HM1-097, serie 1, caja 4, carpeta 7: Buckwalter Albert (1955). Carta a W. Reyburn, 2 de marzo de 1955, f. 1. 
agua'), como en forma independiente, por ejemplo, a la pregunta de si hay agua en el balde, se respondería jaja', huo'o na l'ec ('sí, es lo que hay adentro'). ${ }^{47}$ Sin una mención explícita a la categoría gramatical, la interpretación que Buckwalter hace de l'ec responde de manera adecuada a la categoría gramatical denominada «término de clase» de la lingüística descriptiva moderna (Grinevald, 2000).

En el nivel de expresiones rutinarias, como la de despedida nal'en, Buckwalter sugiere también un análisis detallado de sus partes: na + l'en, por analogía con la forma verbal imperativa l'en ('¡deja!', '¡anda a prepararte!'), y que se da en la expresión que emplea un padre que le dice a su hijo «ideja de llorar!». Entonces, según Buckwalter, un posible origen del saludo toba podría hallarse en la unión del demostrativo na ${ }^{48}$ y la forma verbal l'en ('deja'). ${ }^{49}$

En el interjuego entre su conocimiento práctico del idioma y su intuición de lingüista -o, como él mismo, lo expresa: «Estoy jugando con lo mismo en relación con algunas otras expresiones»,$-{ }^{50}$ propone analizar el adverbio nataq'en ('también') en partes: como artículo demostrativo na ('esto'), más la partícula taq ('otra vez') más la forma verbal en ('es cierto'), aunque asume que «el problema no es tan relevante para que los tobas aprendan más fácilmente a leer» y admite que «si uno tuviera que resolver todos los problemas de manera correcta, se perdería el placer de hacer visible el progreso". ${ }^{51}$ En este sentido, Buckwalter es consciente de la necesidad de conocer la gramática del idioma toba para poder escribirlo, pero reconoce que es menester limitarse a los patrones generales de la gramática y referirse solo a las principales clases de palabras (sustantivo y verbo) para concentrarse de lleno en la traducción de la Biblia. ${ }^{52}$ Sigue, de esta manera, el consejo de Nida de «no quedar atrapado en los atractivos científicos de la lingüística en detrimento del propósito real para el cual acudimos a los indígenas en primer lugar». ${ }^{53}$

No obstante, el anexo gramatical del Vocabulario toba ofrece no solo un análisis apropiado de las clases principales de palabras, sino también un adelanto de lo que luego se consideraron «hallazgos tipológicos» en las gramáticas publicadas entre fines de los setenta y principios de la década del 2000 sobre las lenguas de la familia guaicurú. ${ }^{54}$ En términos de la tipología lingüística actual, la marcación verbal mediante tres conjuntos de prefijos, el isomorfismo entre la marca inactiva de los verbos y la posesión inalienable y el alineamiento jerárquico, entre otros, son rasgos ya señalados por los Buckwalter en su Vocabulario (Messineo, 2020).

47. Mennonite Church USA Archives, A. y L. Buckwalter Papers HM1-097, serie 1, caja 4, carpeta 7: Buckwalter Albert (1954). Carta a W. Reyburn, 20 de diciembre de 1954, f. 2.

48. O artículo determinado, como Buckwalter llama a esta y otras formas posicionales (Buckwalter y Litwiller de Buckwalter, 2001: 328 y 378).

49. Mennonite Church USA Archives, A. y L. Buckwalter Papers HM1-097, serie 1, caja 4, carpeta 7: Buckwalter Albert (1954). Carta a W. Reyburn, 20 de diciembre de 1954, f. 2.

50. Ídem.

51. Ídem.

52. Mennonite Church USA Archives, A. y L. Buckwalter Papers HM1-097, serie 1, caja 4, carpeta 7: Buckwalter Albert (1981). Carta a E. Nida, f. 1.

53. Ibídem, ff. 1-2. (2001)

54. Censabella (2002); Gualdieri (1998); Klein (1978 [ed. en inglés: 1974]); Messineo (2003); Vidal 


\section{4. «Polish up a crazy quilt» o cómo traducir el estilo de las narraciones bíblicas}

La preocupación de los Buckwalter trasciende la cuestión ortográfica y gramatical para enfocarse en expresiones idiomáticas, así como en rasgos estilísticos, de la narrativa toba, que caracterizan como «cargadas de palabras y difíciles de entender sobre todo al tratarse de un tema espiritual». ${ }^{55}$ En otro intercambio con Reyburn, ${ }^{56}$ los Buckwalter plantean un problema de índole estilístico que consideran relevante a la hora de traducir la Biblia a los idiomas indígenas. Si bien su duda es sobre la puntuación, su reflexión va más allá de una cuestión ortográfica. Y sostienen que la puntuación en las historias bíblicas traducidas al toba «no representa la verdadera cadencia de la lengua [toba]", porque «el estilo de las historias [bíblicas] no es el estilo de un toba narrando, sino el de un toba y un americano haciendo todo lo posible para armar una loca colcha de retazos [polish up a crazy quilt]". ${ }^{57}$

Figura 1. Colcha amish-menonita.

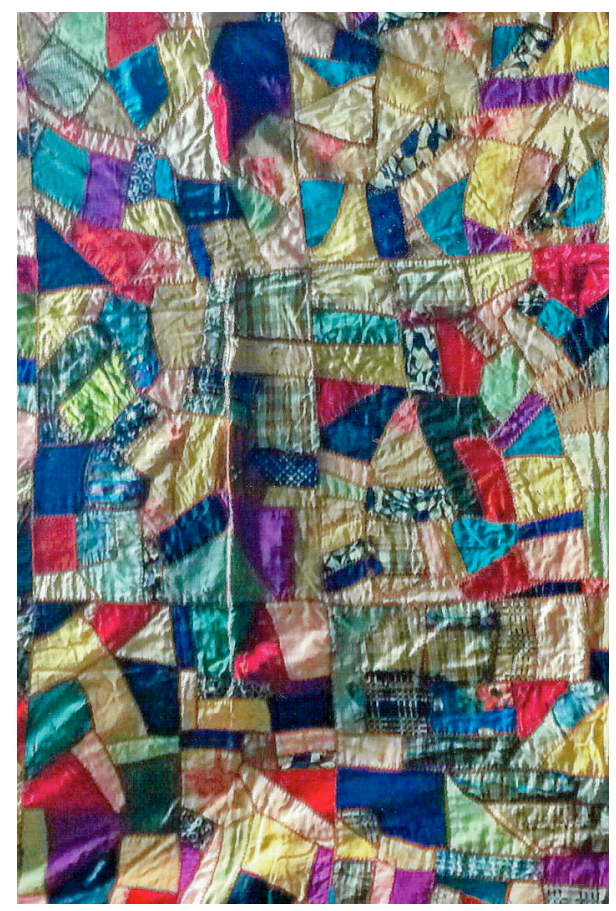

Fuente: Mennonite Historical Library,

Goshen College, Estados Unidos.

55. Mennonite Church USA Archives, A. y L. Buckwalter Papers HM1-097, serie 1, caja 4, carpeta 7: Buckwalter Albert (1954). Carta a W. Reyburn, 20 de diciembre de 1954, f. 2.

56. Mennonite Church USA Archives, A. y L. Buckwalter Papers HM1-097, serie 1, caja 4, carpeta 7: Buckwalter Albert (1955). Carta a W. Reyburn, 2 de marzo de 1955, f. 2.

57. Ídem. 
La figura adjunta corresponde a una crazy quilt, un tipo de colcha tradicional amish-menonita elaborada con restos de tela unidos de una manera aleatoria. Dicha imagen ilustra la labor que significa combinar el estilo de narrar de un toba, el de un norteamericano y el de las historias bíblicas. Esta reflexión de Buckwalter implica reconocer no solo la complejidad del texto bíblico, sino también las particularidades de la narrativa toba. En este sentido, es notable la influencia de Nida, para quien la traducción bíblica supone «la búsqueda del equilibrio entre la comprensión del contexto del original y su correlato en la lengua traducida, teniendo siempre en cuenta los parámetros culturales del lector» (Gallardo San Salvador, 2013: 10). En su trabajo con Taber (Nida y Taber, 1969: 14), Nida sostiene que la Biblia contiene diversos géneros y mezclas de estilos y traducciones de traducciones, lo que la convierte en un texto de por sí altamente complejo. A esto se suman las particularidades de estilo en las distintas lenguas. En este sentido, la narrativa toba presenta características peculiares, muchas de ellas derivadas de la oralidad, tal como la recurrencia de estructuras paratácticas, de oraciones fragmentadas, de una sintaxis regida por la prosodia y de repeticiones y paralelismos, entre otras (Messineo, 2004, 2014).

En la expresión arriba mencionada, Buckwalter también deja entrever su idea de que la tarea del traductor bíblico debe ser colaborativa, es decir, de que el misionero y el traductor indígena tienen que hacer el esfuerzo conjunto de organizar el texto para obtener una versión final coherente y aceptable para ambos.

Nuevamente, la preocupación por la traducción, así como por la escritura de los idiomas indígenas, nos permite vislumbrar el interés y la destreza de los Buckwalter para resolver no solo los problemas fonológicos y gramaticales del idioma toba, sino también los aspectos discursivos involucrados en el proceso de traducción.

\section{Conclusiones}

En este trabajo abordamos las circunstancias que llevaron a los Buckwalter a emprender el estudio de la lengua toba y, posteriormente, el de las otras dos lenguas de la familia (el mocoví y el pilagá). Hemos dado cuenta de sus objetivos, de su formación como lingüistas profesionales y del modo en que este proyecto misionero se enmarcó en un proceso de cambio de paradigma de alcance mundial donde la antropología y la lingüística ocuparon un rol privilegiado. A partir del análisis de las distintas fuentes, así como de las entrevistas realizadas a Lois, hemos puesto en evidencia el profundo conocimiento que ambos tenían no solo de la gramática toba, sino también de las expresiones idiomáticas y del estilo de la narrativa toba.

En principio, el aporte lingüístico de los Buckwalter se enmarca en el contexto de su interés misionero, al ser su objetivo principal que los indígenas se alfabetizaran tanto en su idioma nativo como en español para poder acceder al mensaje cristiano de una forma más profunda y vinculada a sus propias cate- 
gorías. Además, la traducción de la Biblia y la construcción de una cultura letrada alrededor del cristianismo indígena funcionó, junto con otros (Altman, 2017a: 164-197), como un dispositivo de unidad que los menonitas aportaron al movimiento del evangelio tras la disolución de la misión Nam Cum. En este sentido, a causa de motivos mayoritariamente logísticos, la puesta por escrito de algunas formas dialectales de las lenguas en cuestión y no de otras contribuyó también al fomento de cierta unidad lingüística.

Pero el hecho de que el proyecto lingüístico de los Buckwalter se centrara en un conjunto específico de grupos indígenas y estuviera profundamente conectado con sus intereses evangelizadores no debe llevar a menospreciar -como frecuentemente se ha hecho- su particular contribución al estudio de las lenguas chaqueñas. Por un lado, es crucial tener en cuenta la importante y sistemática formación lingüística y antropológica de los Buckwalter, en interacción con reconocidos especialistas del momento. Por otro, el particular contexto de su trabajo misionero determinó, por ejemplo, el hecho de que la comprensión por parte de los propios hablantes de la lengua, y no la adecuación a alguna teoría académica, fuera su parámetro a la hora de tomar decisiones. Esa misma aproximación a la lengua posibilitó una muy rápida apropiación por parte de los hablantes a los materiales escritos, que hizo que el trabajo lingüístico emprendido tuviera gran impacto en los procesos de educación intercultural bilingüe, en la autovaloración y en la legitimación ante la sociedad no indígena, así como en la autonomía de los intelectuales y líderes indígenas en la gestión de sus propias lenguas.

Como todo abordaje, el de los Buckwalter ciertamente tiene sus carencias y preconceptos. Pero el prejuicio académico por el carácter misionero de su presencia en el Chaco no debe impedir el análisis detallado de su enorme trabajo lingüístico y antropológico. De hecho, aunque a veces se olvide, sería imposible pensar la lingüística y la antropología argentina del Chaco sin la tarea de estos y otros menonitas.

\section{Bibliografía}

Altman, Agustina (2017a). El camino del evangelio. Cristianismos y modernidades entre los mocoví del Chaco austral. Tesis de doctorado en Facultad de Filosofía y Letras, Universidad de Buenos Aires.

Altman, Agustina (2017b). «La disolución de Nam Cum en perspectiva: contextos globales de la misión menonita en el Chaco argentino». En: CerIANI Cernadas, César (ed.). Los evangelios chaqueños. Misiones y estrategias indígenas en el siglo xx. Buenos Aires: Asociación Civil Rumbo Sur, págs. 117-143.

AltMAN, Agustina y LóPEZ, Alejandro (2011). «"No hay necesidad de que nos coloquemos uno cerca del otro": territorio e identidad religiosa durante el establecimiento de los menonitas en la Argentina». Actas de las II Jornadas RELIGAR-SUR, Buenos Aires.

AltmAn, Agustina y LóPEZ, Alejandro (2015). «¿Compañeras o acompañantes? Mujeres menonitas misioneras en Argentina». Ciencias Sociales y Religión / Ciências Sociais e Religião, Campinas, 17 (23), págs. 73-113. 
BuckWalter, Albert (1952). «As you might have been». The Gospel Herald, Scottdale, (45), pág. 137.

BuckWALTER, Albert (1953). «"La' yacaya” ('hello, brother' in toba)». The Gospel Herald, Scottdale, (46), pág. 399.

BuckWALTER, Albert (1954). «God bless you, brother». The Gospel Herald, Scottdale, (47), pág. 884.

BuckWALTER, Albert (1972). Vocabulario toba. Edición provisoria. Elkhart: Menonite Board of Mission.

BuckWALTeR, Albert (1987). «Bible translation in the Chaco». Mission Focus, Elkhart, 15 (4), págs. 52-54.

BUCKWALTER, Albert (1995a). «Algunas notas sobre los alfabetos toba, mocoví y pilagá». En: Braunstein, José (ed.). Hacia una nueva carta étnica del Gran Chaco. Las Lomitas: Centro del Hombre Antiguo Chaqueño, págs. 123-130.

BuckWALTER, Albert (1995b). Vocabulario mocoví. Elkhart: Mennonite Board of Missions.

BUCKWALTER, Albert y LITWILLER DE BUCKWALTER, Lois (2001). Vocabulario pilagá. Elkhart: Mennonite Board of Missions.

BUCKWALTER, Albert y LITWILLER DE BUCKWALTER, Lois (2001 [1980]). Vocabulario toba. Elkhart: Mennonite Board of Missions.

BUCKWALTER, Albert y LITWILLER DE BUCKWALTER, Lois (2004). Vocabulario castellano-guaycurú. Elkhart: Mennonite Board of Missions.

Censabella, Marisa (2002). Descripción funcional de un corpus en lengua toba (familia guaycurú, Argentina). Sistema fonológico, clases sintácticas y derivación. Aspectos de sincronía dinámica. Tesis de doctorado en Letras Modernas, Universidad Nacional de Córdoba.

D'ADDARIO, Luciano (2016). «El primer peronismo y la incorporación "protegida" de los pueblos indígenas: un análisis de la Dirección de Protección del Aborigen». V Congreso de Estudios sobre el Peronismo, Buenos Aires.

DomíngueZ, Luisa (2019). Lenguas indígenas en la Argentina. Aportes para una historia de la lingüística en la primera mitad del siglo xx. Tesis de doctorado, Facultad de Filosofía y Letras, Universidad de Buenos Aires.

EDIGER, Tina (1999). Window to the world. Extraordinary stories from a century of overseas mission 1900-2000. Newton: Faith and Life Press.

Gallardo San Salvador, Natividad (2013). «Eugene Nida y su legado. Entrevista con su viuda, M. ${ }^{a}$ Elena Fernández-Miranda Nida». SENDEBAR. Revista de Traducción e Interpretación, Granada, (24), págs. 309-316.

Glozman, Mara (2011). Políticas estatales de regulación lingüística en Argentina. Continuidades y rupturas entre las posiciones de la Academia Argentina de Letras y las orientaciones glotopolíticas del primer peronismo (1930-1955). Tesis de doctorado, Facultad de Filosofía y Letras, Universidad de Buenos Aires.

GoRDILLO, Gastón y HIRSCH, Silvia (2010). «La presencia ausente: invisibilizaciones, políticas estatales y emergencias indígenas en la Argentina». En: GORDILLO, Gastón y HIRSCH, Silvia (eds.). Movilizaciones indígenas e identidades en disputa en la Argentina. Buenos Aires: La Crujía, págs. 15-38.

Graber, Josephus (1952). «The kingdom to the south. Part 3». The Gospel Herald, Scottdale, (45), pág. 138. 
Graber, Josephus (1960). The church apostolic. A discussion of modern missions. Scottdale: Herald Press.

GrineVALD, Collete (2000). «A morphosyntactic typology of classifiers», En: SeNFT, Gunther (ed.). Systems of nominal classification. Cambridge: Cambridge University Press, págs. 50-92.

GUALDIERI, Beatriz (1998). Mocovi (guaicuru). Fonología e morfossintaxe. Tesis de doctorado, Instituto de Estudos da Linguagem, Universidade Estadual de Campinas.

KLEIN, Harriet Manelis (1978 [1974]). Una gramática de la lengua toba: morfología verbal y nominal. Montevideo: Universidad de la República.

LÓPEZ, Alejandro (2017). «"Cerrando filas”: La mirada menonita sobre los vínculos entre las misiones protestantes en el Chaco durante el auge de la "nación católica" (19431949)». En: Ceriani Cernadas, César (ed.). Los evangelios chaqueños. Misiones y estrategias indígenas en el siglo xx. Buenos Aires: Asociación Civil Rumbo Sur, págs. 41-70.

MESSINEO, Cristina (2003). Lengua toba (guaycurú). Aspectos gramaticales y discursivos. Múnich: Lincom Europa Academic Publisher.

MESSINEO, Cristina (2004). «Toba discourse as verbal art». Anthropological Linguistics, Indiana, 46 (4), págs. 216-238.

MESSINEO, Cristina (2014). Arte verbal qom: consejos, rogativas y relatos (textos y comentarios de Mauricio Maidana). Buenos Aires: Editorial Rumbo Sur.

MESSINEO, Cristina (2020). «Lingüistas intuitivos. La labor de los misioneros menonitas entre los toba/qom del Chaco argentino». XI Congreso Internacional de Lingüística Misionera, Santa Rosa.

MiLleR, Elmer (1979). Los tobas argentinos. Armonía y disonancia en una sociedad. México: Siglo XXI Editores.

MILLER, Elmer (1995). Nurturing doubt: from mennonite missionary to anthropologist in the Argentine Chaco. Illinois: University of Illinois Press.

NIDA, Eugene y TABER, Charles (1969). The theory and practice of translation. Leiden: $\mathrm{E}$. J. Brill.

REYBuRn, William (1954a). A short descriptive grammar of the toba (El Espinillo dialect). Elkhart. Manuscrito inédito.

REYBURN, William (1954b). «Some problems in providing toba Bibles». The Gospel Herald, Scottdale, (47), págs. 614-615.

REyburn, William (1954c). The toba indians of the argentine Chaco. An interpretive report. Elkhart: MBMC.

ReYbuRn, William (2002). Marching through Babel. Bloomington: Xlibris Corporation.

SAPIR, Edward (1949). «The psychological reality of phoneme». En: MANDELBAUM, David (ed.). Selected writings of Edward Sapir in language, culture and personality. California: University of California Press, págs. 46-60.

SHANK, Josephus (1951). We enter the Chaco Indian work. Elkhart: Mennonite Board of Missions and Charities.

Sociedad Bíblica Argentina (1980). Nuevo Testamento en toba/qom. Buenos Aires: Sociedades Bíblicas Unidas.

Sociedad Bíblica Argentina (1991). Moqoit la'qaatqa. El Antiguo Testamento corto en mocoví. Seúl: Sociedades Bíblicas Unidas. 
Sociedad Bíblica Argentina (1993a). Nuevo Testamento pilagá. Buenos Aires: Sociedades Bíblicas Unidas.

Sociedad Bíblica Argentina (1993b). Selección de libros Antiguo Testamento toba/qom. Buenos Aires: Sociedades Bíblicas Unidas.

Sociedad Bíblica Argentina (2005 [1988]). Nuevo Testamento en mocoví / Moqoit la'qaatqa. Buenos Aires: Sociedades Bíblicas Unidas.

The Gospel Herald (1951). «Missions». The Gospel Herald, Scottdale, (44), pág. 399.

TrubetZkoy, Nikolái (1973 [1939]). Principios de fonología. Madrid: Cincel.

VIDAL, Alejandra (2001). Pilagá grammar (guaykuruan family, Argentina). Ann Arbor: University of Michigan Dissertation Services.

Wright, Pablo (2008). Ser-en-el-sueño. Crónicas de historia y vida toba. Buenos Aires: Biblos.

Fecha de recepción: 22 de enero de 2021

Fecha de aceptación: 6 de abril de 2021

Fecha de publicación: 22 de diciembre de 2021 